\title{
De patrimonios culturales y sus categorías
}

\section{Of cultural heritage and its categories}

Honorio M. Velasco

Catedrático de Antropología Social. Departamento de Antropología Social y Cultural. UNED hvelasco@fsof.uned.es

\section{ANIVERSARIO DE LA GAZETA DE ANTROPOLOGÍA}

NÚMERO COORDINADO POR FRANCISCO CHECA OLMOS Y CELESTE JIMÉNEZ DE MADARIAGA

\begin{abstract}
RESUMEN
La gestación de lo que luego sería la Convención del Patrimonio Cultural Inmaterial comienza poco después de la aprobación de la Convención del Patrimonio Mundial en 1972, y eso muestra que el contenido de ésta dejó insatisfechos a muchos países. Las categorías que se incluyeron en aquella se mencionaban ya en los primeros documentos y han quedado finalmente diferenciadas agrupándose en cinco epígrafes, que sin embargo se muestran del todo imprecisos y, lo que es más importante, dejan indefinido el ámbito de aplicación. De todos modos, el Patrimonio Cultural Inmaterial se ha convertido en un capital simbólico relevante y los Estados, y también las comunidades, se disputan la inclusión de sus elementos en las listas UNESCO cuya etiqueta de valoración es ya paradigmática: 'Patrimonio de la Humanidad'.
\end{abstract}

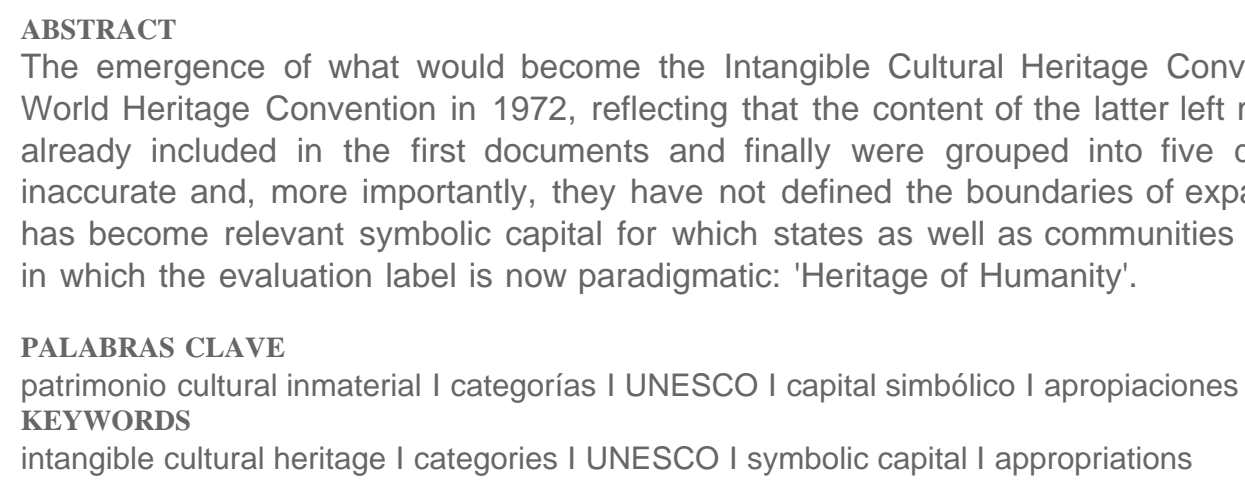
in which the evaluation label is now paradigmatic: 'Heritage of Humanity'.

PALABRAS CLAVE

patrimonio cultural inmaterial I categorías I UNESCO I capital simbólico I apropiaciones KEYWORDS

intangible cultural heritage I categories I UNESCO I symbolic capital I appropriations

The emergence of what would become the Intangible Cultural Heritage Convention began shortly after the adoption of the World Heritage Convention in 1972, reflecting that the content of the latter left many countries unsatisfied. The categories were already included in the first documents and finally were grouped into five distinct sections, which are nevertheless quite inaccurate and, more importantly, they have not defined the boundaries of expansion. In any case, Intangible Cultural Heritage has become relevant symbolic capital for which states as well as communities dispute the inclusion of items on UNESCO lists,

\section{Denominación}

La denominación de la categoría que adoptó UNESCO en la Convención de 2003 "Patrimonio Cultural Inmaterial" sustituía a anteriores y distintas formulaciones que la propia institución internacional había empleado anteriormente. La percepción de su contenido y su reconocimiento aparece casi inmediatamente después de la Convención de Patrimonio Mundial (1972), en la serie de Conferencias Intergubernamentales sobre Políticas Culturales que organizó por continentes, en las que se hicieron habituales referencias a la "cultura espiritual", a las tradiciones, a la "cultura popular", etc. En la de Yogyakarta en 1973 ya se subrayaba la importancia de las "artes tradicionales" en Asia, "pues ofrecen testimonio de los valores espirituales de los pueblos" (punto 8). Y expresamente en una de las recomendaciones se menciona "la conservación de las tradiciones populares" (punto 17 c) y los "festivales" (punto 17 m) (1). La Conferencia Intergubernamental de Accra en 1975 subrayó el valor de la diversidad cultural y como consecuencia propone la salvaguardia de "las lenguas africanas y de la tradición oral" (puntos 42 y 44) y el fomento de "las artes tradicionales y populares". Y en la Recomendación $n^{0} 1$ se demanda: "dar a las lenguas africanas el lugar que les corresponde en la vida cultural", "se recojan y conserven, antes de que sea tarde... las costumbres, los hábitos y las tradiciones", "se registren y pongan al alcance de todos todas la formas de expresión artística". En la 
Recomendación 2, dirigida a los Estados, se dice que realicen inventarios "tanto del patrimonio material, los lugares y monumentos, como de los objetos de arte y artesanía, las tradiciones orales, la música y la danza, las ceremonias y las fiestas". En la Recomendación 12 se urge a la conservación del patrimonio musical y de la danza, en la 13 a apoyar a los artistas tradicionales, en la 41 a los deportes y juegos tradicionales y a la necesidad de "ensamblarlos en el patrimonio nacional...". La Conferencia de Bogotá de 1978 aprobó una Declaración en cuyas recomendaciones se insiste en la necesidad del rescate y la salvaguardia del Patrimonio vinculado indisolublemente a la identidad cultural de los pueblos y a su autenticidad, y en la incorporación en las estrategias del desarrollo económico y social de ese rescate. Tras una serie de recomendaciones dedicadas a los centros históricos, monumentos, etc., la recomendación 31 sitúa la música y la danza como uno de los elementos esenciales de la identidad cultural e insta a su promoción. La recomendación 33 hace lo mismo con las artes populares y de la cultura popular como elementos fundamentales del patrimonio de los pueblos. La Declaración de México en 1982 se elabora como cierre de la serie de las Conferencias Intergubernamentales sobre Políticas Culturales y se sintetizan y sistematizan en ella las recomendaciones anteriores. Se trata de un documento relevante. En los considerandos primeros contiene una actualizada definición de cultura como el "conjunto de rasgos distintivos espirituales y materiales, intelectuales y afectivos que caracterizan a una sociedad o grupo social". En el punto 4 afirma que "todas las culturas forman parte del patrimonio común de la humanidad". Los puntos 23 a 26 desglosan firmes pronunciamientos respecto al patrimonio cultural. En el 23 afirma que el patrimonio lo integran "las obras materiales y no materiales que expresan la creatividad de un pueblo" y hace mención expresa de la lengua, los ritos, las creencias, los lugares y monumentos históricos, la literatura, las obras de arte, los archivos y bibliotecas. El 24 asienta el derecho y deber de los pueblos de conservar sus patrimonios culturales. El 25 identifica las principales amenazas al patrimonio. Y el 26 intensifica la necesidad de aplicar el principio de restitución.

La Conferencia General de la UNESCO celebrada en París en 1989 elabora, por fin, un documento específico relativo a todos esos contenidos apuntados en las conferencias anteriores y utiliza el término para designarlos de "Traditional Culture and Folklore" en inglés, pero en la versión en español aparece como "Cultura tradicional y popular". La Declaración para la salvaguardia de éstas es tenida como el antecedente expreso de la Convención de 2003. Sucede en realidad a otra determinación de la Conferencia General anterior de 1988 en la que se acordó hacer una Recomendación a los Estados miembros sobre la "Salvaguardia del Folklore", y resulta muy significativa la traducción al español que conlleva la sustitución del término Folklore y el hecho de que tampoco en inglés se haya vuelto a utilizar.

Entre 1995 y 1999 se realizaron una serie de seminarios regionales dedicados a evaluar la aplicación de la recomendación que culminan en la Conferencia celebrada en Washington en 1999 bajo la responsabilidad de la Smithsonian. En 1994 ya se había enviado a los Estados miembros un cuestionario sobre la Recomendación y en ese tiempo se había creado en la propia UNESCO una unidad de "patrimonio cultural inmaterial". Mientras en la 155 Conferencia General celebrada en 1998 se aprobó el proyecto de "Proclamación de obras maestras del Patrimonio oral e intangible de la Humanidad" y se comenzaron los estudios para el programa "Tesoros humanos vivientes". Esperablemente en la Conferencia de Washington de 1999 se reafirma, por un lado, el sesgo de la Convención de 1972 hacia el Patrimonio cultural material y, por otro lado, se recoge la pluralidad de términos empleados para referirse a lo intangible. Las discusiones reflejadas en el informe muestran una generalizada opinión acerca de la inadecuación del término Folklore del que incluso se dice ser "problemático". Fue en las conclusiones del seminario celebrado en Nueva Caledonia en 1999, donde ya se expresaba un rechazo al término "folklore", basado en la convicción de que era un término peyorativo, respondía a actitudes colonialistas pues se aplicaba fundamentalmente a las costumbres y tradiciones indígenas y no por parte de ellos sino por los europeos. En la Conferencia de Washington tras constatar su inadecuación se comprueba la inexistencia de consenso en cuanto a los términos sustitutorios y se concluye la conveniencia de realizar un estudio sobre terminología más apropiado aceptando su uso provisional y su equivalencia a "patrimonio oral", "conocimientos y destrezas tradicionales", "patrimonio intangible", "formas de saber, ser y hacer" (Plan de Acción, A.2). También aparece en la discusión una crítica al término "intangible", basada en el argumento de que no es posible separar el patrimonio tangible del intangible (Plan de Acción, A.3). Y tampoco el término "tradicional" es aceptable para buena parte de los congresistas pues implica negar o dejar de apreciar las innovaciones (Plan de Acción A.11). Ni el término 
"popular" puesto que no refleja suficientemente la relevancia que tiene en cuanto a la expresión de las identidades culturales. Aunque en el documento no se refleja, la insatisfacción respecto al término "popular" tiene como trasfondo el uso creciente de éste para referirse a las formas culturales de la globalización.

En 2001 un informe del Director General de la UNESCO que se dirige a la preparación de una nueva normativa sobre estos asuntos se pronuncia decididamente sobre el rechazo del término Folklore y la adopción de "patrimonio cultural inmaterial", denominación que se consolida ya en la Declaración de Estambul de 2002 (2). En paralelo persiste la otra denominación de Patrimonio oral e intangible en las Proclamaciones de Obras maestras de la Humanidad, hasta el desarrollo de las listas previstas en la Convención de 2003, la representativa y la de elementos en riesgo de desaparición, que se produce con posterioridad a 2007.

"Inmaterial" es un término no obstante que no deja de tener inconvenientes, fundamentalmente porque, como ha sido señalado reiteradamente, muchos de los elementos así proclamados son estrictamente materiales (espacios, artes performativas, fiestas, músicas interpretadas con instrumentos característicos, artesanías, etc.) y por otro lado, los reconocidos como Patrimonio de la Humanidad (según la Convención de 1972) que han sido tenidos como propiamente pertenecientes a la cultura material -como han señalado numerosos analistas- no están sino cargados de significados y valores, y se encuentran igualmente vinculados a las identidades culturales de modo que en ellos lo inmaterial no es accesorio sino sustantivo.

\section{Categorías}

La Recomendación de 1989 contiene una expresa definición de folklore (la traducción al español utiliza la expresión equivalente que indica el propio documento "Folklore or traditional and popular culture") en la cual como formas de él se especifican: la lengua, la literatura, la música, la danza, los juegos, la mitología, los rituales, las costumbres, las artesanías, la arquitectura y otras artes. Se trata de una enumeración no cerrada que en alguna medida recogía aquellas que en la serie de Conferencias Intergubernamentales de Políticas Culturales realizadas a partir de 1972 se fueron apuntando a la vez que de esa manera se ponían en evidencia las lagunas de la Convención sobre Patrimonio Cultural y Natural. Se mencionaron las lenguas, la tradición oral, los festivales, la música y la danza, las ceremonias, las artes tradicionales y artesanías y, en general, las tradiciones populares. Los manuales de "folklore" contenían un abanico mucho más amplio y sistematizado de categorías, pero parece que no sirvieron de modelo a los redactores de la Recomendación. Sin embargo, las categorías señaladas se revelan como sensibles pues fueron destacadas en las Conferencias celebradas en Yogyakarta, en Accra, en Bogotá o en México a propuesta de los gobiernos participantes mostrando el interés diferenciado de ellos en contraste, por ejemplo, con la Conferencia de Helsinki en 1972 centrada exclusivamente en el Patrimonio Material.

La Proclamación de las Obras Maestras del Patrimonio Oral e Intangible de 2001 contó con la tarea realizada por un grupo de expertos reunidos en Turín en ese mismo año que proporcionó una "nueva definición del patrimonio oral e intangibe", sin embargo en esa definición no se especifican categorías o formas de expresión. La convocatoria diferenciaba simplemente entre espacios culturales y formas expresivas. Pero el punto 7 del documento que se puso a disposición de los Estados para presentar sus candidaturas (Guide for presentation of candidature files 2001) se refiere a dos tipos de manifestaciones: a) formas de expresión cultural como performances musicales o teatrales, rituales o fiestas diversas y b) espacios culturales donde se concentran actividades tradicionales.

Y en el punto 8, a título de ejemplo, menciona: lenguas, tradiciones orales, artes dramáticas, conocimientos prácticos ligados a la cultura material.

Entre la Recomendación de 1989 y los documentos de la Proclamación de Obras Maestras se percibe por un lado el énfasis o la selección puestos en determinadas formas sugeridos desde algunos Estados 
y, por otro lado, cierta falta de especificación que de hecho evitaba entrar en el problema de los límites del ámbito del Patrimonio Inmaterial. Además de la inclusión de los "espacios culturales", categoría apoyada ya anteriormente en algunos de los Seminarios citados poniendo como modelos determinados lugares tales como la Plaza Jemaa el-Fna en Marrakech. La única lógica explícita se justifica por haber dado relevancia a los acontecimientos de ocurrencia regular o a espacios organizados acogiendo igualmente acontecimientos de ocurrencia regular.

La Convención de 2003, sin embargo, aborda intencionadamente, y por lo tanto proporciona reconocimiento, a determinadas categorías del Patrimonio Inmaterial, especificadas como: a) tradiciones y expresiones orales incluido el idioma como vehículo del patrimonio cultural inmaterial; b) artes del espectáculo; c) usos sociales, rituales y actos festivos; d) conocimientos y usos relacionados con la naturaleza y el universo; y e) técnicas tradicionales artesanales.

Cabe subrayar que tampoco en esta ocasión reproduce las caracterizaciones de elementos que suelen utilizar en los manuales de Folklore ni la relación que suele reproducirse en los manuales de Etnografía. Y efectivamente tampoco puede tratarse de una clasificación sistemática de los dominios inmateriales de la cultura. Más bien son grandes apartados o ámbitos, heterogéneos en su contenido e indefinidos en sus límites, como bien se ha mostrado en la aplicación a los elementos ya reconocidos hasta esa fecha como Obras Maestras (2001, 2003, 2005 ) y a los posteriores integrados en la Lista Representativa y en la Lista de los que requieren medidas urgentes de salvaguardia. No existe por otra parte documentación alguna de desarrollo de la Convención en la que se hayan desglosado. Guardan por tanto una calculada ambigüedad y asistematicidad. $Y$ es oportuno señalar igualmente la desaparición de la categoría "espacios culturales" que en las proclamaciones anteriores tuvo tanta relevancia y la evitación de las lenguas en cuanto tales como objetos concretos de protección. Habría que señalar que, en todo caso, han sido adoptadas por la UNESCO como dentro de los rasgos de identificación de cada elemento que se propone para ser incluido en las listas, pues en los protocolos de las candidaturas se exige explícitamente que se indique qué tipo es o a qué categoría se acoge.

De todos modos, aunque pueda pensarse que fueron introducidas tomando como modelos las que se diseñaron para la lista del Patrimonio cultural y natural (Convención 1972) no sigue la misma lógica que ésta, atenta más bien a delimitar unidades en distinto grado de complejidad (monumentos, conjuntos, lugares). Se perfilan atendiendo a parte de la gran variedad de elementos de la cultura, asumiendo alguna distinción entre elementos más o menos dependientes de cultura material, pues la diferencia entre tradición oral y artesanías parece marcada en esa dirección. No obstante, no encuentra fundamento en esa línea pues se suele reconocer que la tradición oral, precisamente, es un proceso sustancial a las artesanías, cuyo aprendizaje suele estar basado en la imitación de los modelos más habilidosos, y en la adecuada recepción de los acertados mensajes e informaciones valiosas que pasan de las generaciones mayores a las jóvenes.

Tales categorías, como se ve, han sufrido cambios en la última década, en los documentos programáticos, y también en la aplicación a los distintos elementos incorporados a las listas. En el cuadro siguiente se reflejan las distintas categorías que se han empleado en los expedientes de candidatura de los elementos, expedientes que han sido aprobados por UNESCO, pues se han incorporados a las listas. 


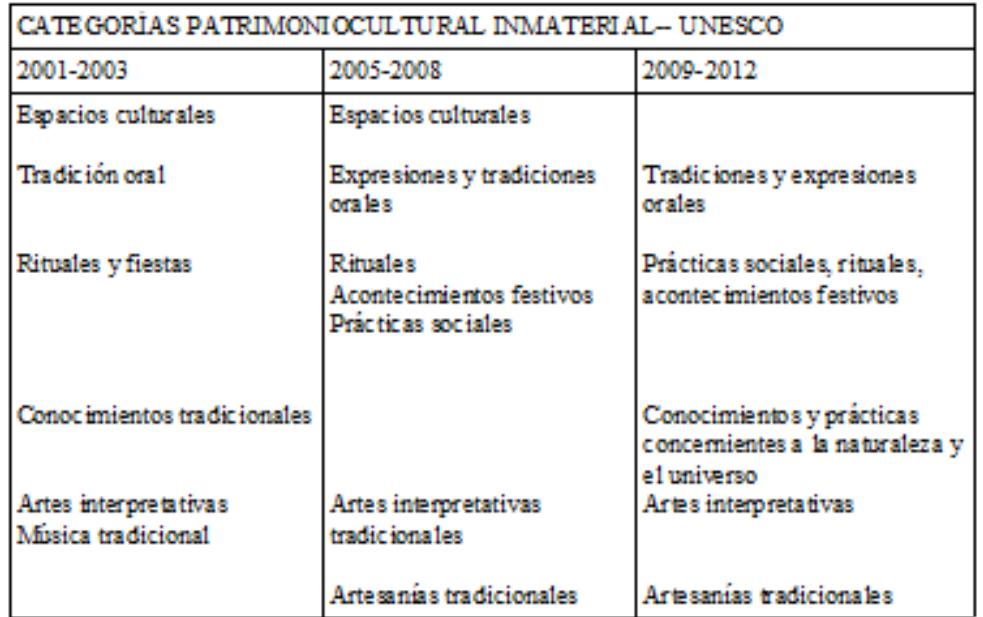

Fuente: elaboración propia sobre documentación ofrecida en las listas UNESCO de PCI

En las listas entonces Ilamadas de "Obras Maestras" anteriores a la aprobación de la Convención en 2005 no figuraban las Artesanías tradicionales. Y sí aparecía la Música tradicional que luego dejó de aparecer. En las listas (ahora llamadas ya Representativa y de riesgo) del 2005 al 2008 no figuran los Conocimientos tradicionales. Además, se habían englobado los Rituales y fiestas en otra categoría mayor, la de Prácticas sociales, Rituales y Acontecimientos festivos. Las Prácticas sociales pueden extenderse de forma indefinida. En las listas de 2009 y 2010 desaparece la de Espacios culturales y reaparece la de Conocimientos y prácticas concernientes a la naturaleza y el universo. Todo ello indica que se trata de categorías débilmente consolidadas, relativamente abiertas e imprecisamente delimitadas. Según se aprecia en uno de los documentos procedente de Corea (este país y Japón tenían ya desde la década de los 50 medidas de protección para elementos del patrimonio inmaterial y habían iniciado el programa de protección a los tesoros vivientes), a partir de la Convención se produjo una cierta tensión entre algunos países, como la propia Corea, que mantenían una definición más estricta del $\mathrm{PCl}$ en la que sólo cabía una serie fija de categorías simples, tales como música, danza, teatro, juegos, ritos, artes marciales, artesanías y gastronomía y otros países, a los que se sumaba la propia UNESCO, que se pronunciaban por una definición laxa con categorías de aplicación múltiple. La incorporación sucesiva de elementos a la lista muestra que esta última tendencia se ha instalado con fuerza y los límites del PCI siguen aún estando por determinar.

La aplicación de las categorías a los elementos presentados para ser inscritos en las Listas UNESCO se muestra en las siguientes tablas. La primera recoge los proclamados en 2001 y 2003 , y la segunda los proclamados en 2010 y 2011. 


\begin{tabular}{|c|c|}
\hline \multicolumn{2}{|c|}{$\begin{array}{l}\text { CATEGORIAS PATRIMONIO CUL TURAL INMA TERIALUNB SCO LISTA OBRAS } \\
\text { MAESTRAS DE LA HUMANIDAD 2001-2003 }\end{array}$} \\
\hline Espacios Culturales & 6 \\
\hline Espacios Culturales/ Música Tradicional & 1 \\
\hline Música Tradicional & 8 \\
\hline Tradición Oral/Música Tradicional & 1 \\
\hline Tradición Oral & 5 \\
\hline Tradición Oral/ Rituales y fiestas & 2 \\
\hline Rituales y fiestas & 7 \\
\hline Conocimientos tradicionales/ Tra dición Oral & 2 \\
\hline Conocimientos tradicionales & 4 \\
\hline Artes inferpretativas & 9 \\
\hline TOTAL & 45 \\
\hline Espacios culturales & $15,55 \%$ \\
\hline Música Tradicional & $22,22 \%$ \\
\hline Tradición Oral & $22.22 \%$ \\
\hline Rituales y fiestas & $20 \%$ \\
\hline Conocimiento tradicionales & $13.33 \%$ \\
\hline Artes interpretativas & $20 \%$ \\
\hline
\end{tabular}

En la primera tabla (2001-2003) predominan los elementos caracterizados por una sola categoría, Espacios Culturales, Música Tradicional, Rituales y fiestas, Artes interpretativas, etc. Y se aprecia una distribución muy equilibrada entre ellas, probablemente fruto de una meditada decisión de forma que las proclamaciones dejaran el ámbito general suficientemente representado. No puede tomarse pues como muestra significativa de la preponderancia de determinados tipos de elementos en el Patrimonio Cultural Inmaterial, sino que más bien es muestra ilustrativa que se ofrece para estimular a los Estados a presentar nuevas candidaturas.

\begin{tabular}{|c|c|}
\hline \multicolumn{2}{|c|}{$\begin{array}{l}\text { CATEGORIAS PA TRIMONIO CUL TURAL INMATERIAL UNESCO LISTAS } \\
\text { REPRESENTATIVA (Y DE URGENCIA) DEL P. C. I. DE LA HUMANIDAD } 2010 \\
11\end{array}$} \\
\hline Tradiciones y expresiones orales & 1 \\
\hline Tradiciones y expresiones orales' Artes del espectácub & 3 \\
\hline $\begin{array}{l}\text { Tradiciones y expresiones orales' Prácticas Sociales, rituales y } \\
\text { aco ntecimientos festivos }\end{array}$ & 5 \\
\hline $\begin{array}{l}\text { Tr adiciones y expresiones orales /Artes del espectác ulo/ Prácticas } \\
\text { Sociales, rituales y acontecimientos festivos }\end{array}$ & 7 \\
\hline $\begin{array}{l}\text { Tradiciones y expresiones orales' Artes delespectáculo/ } \\
\text { Artesanías Tr adicionales }\end{array}$ & 4 \\
\hline $\begin{array}{l}\text { Tradiciones y expresiones orales/Prácticas Sociales, rituales y } \\
\text { acontecimientos festivos/Conocimientos y prácticas } \\
\text { concernientes a la naturalez a y el universo }\end{array}$ & 2 \\
\hline $\begin{array}{l}\text { Tradiciones y expresiones orales' Práctic as Sociales, rir uales y } \\
\text { acontecimientos festivos/Artesanías Tradicionales }\end{array}$ & 4 \\
\hline $\begin{array}{l}\text { Tradiciones y expresiones orales' Artes del espectácub/ Prácticas } \\
\text { Sociales, rituales y acontecimientos festivos/ Conocimientos y } \\
\text { prácticas concer nientes a la natur aleza y el umiver so }\end{array}$ & 2 \\
\hline $\begin{array}{l}\text { Tradiciones y expr esiones orales' Artes del espectáculo/ Prácticas } \\
\text { Sociales, rituales y acontecimientos festivos / Artesarías } \\
\text { Tradicionales }\end{array}$ & 5 \\
\hline $\begin{array}{l}\text { Tradiciones y expresiones orales' Prácticas Sociales, rituales y } \\
\text { acontecimientos festivos/Conocimientos y práctic as } \\
\text { concernientes a la naturalez a y el universo/Artesanías } \\
\text { Tradicionales }\end{array}$ & 3 \\
\hline $\begin{array}{l}\text { Tradiciones y expr esiones orales' Artes del espectáculo/ Prácticas } \\
\text { Sociales, rituales y acontecimientos festivos / Conocimient os y. } \\
\text { prácticas concer nientes a la natur aleza y el univer so/ Artesanias } \\
\text { Tradicionales }\end{array}$ & 7 \\
\hline
\end{tabular}

\begin{tabular}{|c|c|}
\hline Artes del espectáculo & 7 \\
\hline $\begin{array}{l}\text { Artes del espectáculo.Prácticas Sociales, } r \text { it uales y } \\
\text { acontecimientos festivos }\end{array}$ & 2 \\
\hline $\begin{array}{l}\text { Artes del espectáculo/ Conocimientos y práctic as concernientes a } \\
\text { la naturalez a y el universo }\end{array}$ & 1 \\
\hline Práctic as Sociales, rituales y acontecimientos festivos & 10 \\
\hline $\begin{array}{l}\text { Práctic as Sociales, rituales y acontecimientos festivos/' } \\
\text { Conocimientos y práctic as concernientes a la naturalez a y el } \\
\text { univer so }\end{array}$ & 3 \\
\hline $\begin{array}{l}\text { Práctic as Sociales, rituales y acontecimientos festivos/ } \\
\text { Conocimientos y práctic as concernientes a la naturaleza y el } \\
\text { univer so/Artesanías Tradicionales }\end{array}$ & 1 \\
\hline $\begin{array}{l}\text { Práctic as Sociales, rituales y acontecimientos festivos/Artesanías } \\
\text { Tradicionales }\end{array}$ & 2 \\
\hline $\begin{array}{l}\text { Conocimientos y práctic as concernientes a la naturaleza y el } \\
\text { univer so }\end{array}$ & 3 \\
\hline $\begin{array}{l}\text { Conocimientos y práctic as concernientes a la naturaleza y el } \\
\text { univer so/ Artesanas Tradicionales }\end{array}$ & 2 \\
\hline Artesanías Tradicionales & 6 \\
\hline TOTAL & 80 \\
\hline Tradiciones y Expresiones Orales & $50,1 \%$ \\
\hline Artes del Espectaculo & $38,7 \%$ \\
\hline 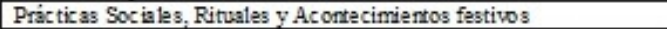 & $66,2 \%$ \\
\hline $\begin{array}{l}\text { Conocimientos y prácticas concemientes a la ra turaleza y el universo } \\
\end{array}$ & $28,7 \%$ \\
\hline Artesanias tradicionales & $47,5 \%$ \\
\hline
\end{tabular}

Fuente: Informes de las Candidaturas presentados a UNESCO

En la segunda tabla destacan de forma abrumadora las caracterizaciones mediante categorías combinadas. Es común que a los elementos se les haya caracterizado por tres o más. Aunque ciertamente en la mayoría de los casos tiene más relevancia alguna de ellas. El hecho de que parezca más adecuado servirse de varias para su caracterización indica sobre todo que se trata generalmente de lo que M. Mauss Ilamaba "hechos sociales totales". En buena medida es un factor que se supone eleva la importancia de un elemento, o al menos así se expresan los informes de las candidaturas. Si las categorías se tomaran como componentes diferenciados entonces aparecen también notables 
diferencias. Predominan sobre todo aquellos elementos tipificados como Prácticas sociales, Rituales y Acontecimientos festivos y a continuación las Tradiciones y expresiones orales, las Artesanías tradicionales y las Artes interpretativas. Presumiblemente eso puede indicar que la categoría Prácticas Sociales, Rituales y Acontecimientos festivos es muy amplia y abarca una gran variedad de elementos, pero no es menos digno de resaltar que parece estar operando como primera referencia del Patrimonio Cultural Inmaterial, seguida por las Tradiciones y expresiones orales y por las Artesanías.

A lo largo de una década, y tras haberse provocado con enorme eficacia una afanosa búsqueda de reconocimientos UNESCO por parte de muchos Estados para su Patrimonio inmaterial, a la vez que se iba ampliando el número de elementos incorporados a las Listas, ha ido ensanchándose la variedad recogida y se ha ido apreciando mejor la complejidad que tiene su caracterización. El otro lado de esta constatación es la evidencia de que las categorías previstas se han ido mostrando escasamente significativas, deficientemente conformadas e insuficientes para operar como etiquetas únicas de tipificación. Y continúa sin resolverse la cuestión de los límites. Hoy hay multitud de propuestas de reconocimiento por parte de Instituciones públicas y privadas para muy variados elementos (los ejemplos son innumerables), lo que indica la existencia de una percepción generalizada de ausencia de límites. En un listado reciente en España aparecen, por ejemplo, Aste Nagusia o Semana Grande de Bilbao, el Filandón de León, el Camino de Santiago, la Procesión de la Virgen de la Salud de Algemesí, la Leyenda de los amantes de Teruel, las Fallas de Valencia, la Tradición de la Virgen del Pilar de Zaragoza, la Leyenda del Lagarto de la Malena de Jaén, el Carnaval de Cádiz y la Bienal de Flamenco de Sevilla, las diez más votadas por el público entre 45 candidaturas. Mientras que al mismo tiempo se acentúa otra percepción, la de que los reconocimientos que proporciona UNESCO responden en buena medida a decisiones basadas en acuerdos políticos que se rigen por compensaciones, entre otras cosas. Ambos aspectos conducen a pensar en un posible peligro de desvirtuación del reconocimiento y tal vez de trivialización.

\section{Excepcionalidad versus representación}

De una destacada manera, la Convención de 2003 sobre Patrimonio Inmaterial lo ha asociado con los "sentimientos de identidad y continuidad" de las comunidades y grupos sociales y con "el respeto a la diversidad cultural y la creatividad humana", a diferencia de la de 1972, la del Patrimonio mundial (cultura material), que se limitó a recalcar la "importancia", el "interés", el "valor universal excepcional" o el "empobrecimiento" en caso de deterioro o pérdida del patrimonio material. Esta diferencia supone un cambio en la concepción del valor del patrimonio cultural: del material o más propiamente llamado "patrimonio mundial cultural y natural", al cual se somete a una valoración configurada en escala cuya máxima expresión se formula como "universal excepcional" y que se entiende como requisito para recibir el reconocimiento de "patrimonio de la humanidad", al llamado "patrimonio cultural inmaterial", al que se atribuye una valoración cualitativa en términos de vinculación de las comunidades y grupos humanos con ellos en tanto que factores de generación y fomento de identidad y de continuidad (adviértase ésta como una forma de redefinir la tradición) y en tanto igualmente que aportaciones a la diversidad cultural y muestras de la creatividad. Es particularmente significativo que UNESCO haya sustituido las primeras cualificaciones de "obras maestras de la humanidad" por listas "representativas" y de "riesgo". Se ha renunciando claramente a la expresión de "obra maestra" y a las connotaciones de posición superior en una escala que conlleva, pues se entienden difícilmente compatibles con el respeto a la diversidad. En cambio la "representatividad" es un valor que se genera y refuerza refiriendo el elemento al propio contexto. En principio responde a la incomparabilidad entre los elementos, evitando ordenarlos en una escala y en la medida en que se inserta en un muestrario de la diversidad y de la creatividad no se deja cerrado en su propio entorno sino que se ofrece en comunicación al resto de los pueblos del mundo. UNESCO ha asumido así un papel difusor -y mediador- en la comunicación intercultural. No obstante, no puede obviarse el propio procedimiento de la inclusión en las Listas, el cual se produce por selección entre un conjunto de candidaturas propuestas (a su vez en la mayoría de los casos seleccionadas por cada Estado de entre un conjunto mucho más amplio). Este proceso de selección produce un cierto efecto de escala y en todo caso otorga relevancias según grados que se corresponden con los comités 
Otro aspecto destacable del cambio en el sistema de valores que se atribuyen a uno y a otro es el hecho de que el "interés" y la "importancia" del primero, el patrimonio cultural y natural, se remiten a ámbitos de legitimación académica: "desde el punto de vista de la historia, el arte, la ciencia", "desde el punto de vista histórico, estético, etnológico o antropológico" para el caso de monumentos, conjuntos y lugares (Convención 1972, artículo 1); y "desde el punto de vista estético o científico", "desde el punto de vista de la ciencia, la conservación o la belleza natural" para el caso de monumentos naturales, zonas o lugares naturales (artículo 2). Mientras que el sistema de valores en el caso del patrimonio cultural inmaterial remite a las comunidades, los grupos o los individuos que los reconocen como patrimonio (Convención 2003, artículo 2.1). No hay en este caso ámbitos diferenciados de legitimación académica (ya sean artes o ciencias), por lo que cabría señalar que basta y se considera suficiente la referencia "cultura". Entre una y otra Convención se percibe un desplazamiento del foco generador de la relevancia del patrimonio cultural. En cuanto al Patrimonio mundial, se sitúa en el Arte y la Ciencia; mientras que en cuanto al Patrimonio inmaterial, se sitúa en las comunidades y grupos. Con el Patrimonio inmaterial se ha producido en principio un giro relevante en la gestión de la cultura que ya no se restringe a aquello previamente reconocido por los ámbitos académicos (y de configuración principalmente occidental) sino que está abierta a la pluralidad de los pueblos del mundo en su doble acepción de pueblo común y de sociedades diferenciadas.

En la formulación más básica el valor "Patrimonio Cultural" se expresa en términos de referencia a delimitaciones socio-territoriales (incluyendo las referencias a entidades étnicas o sociedades generales), de las cuales sólo UNESCO ha asumido la facultad de otorgar una categoría anteriormente empleada en la presunción de consideraciones etnocéntricas (muchos pueblos se tienen a sí mismos, y a sus obras, como mejores representantes de la especie humana) pero que en su condición de institución internacional se considera legitimada para ello. Se trata del valor formulado como "Patrimonio de la Humanidad" (Art. 16 de la Convención de 2003), tal título, o valor anteriormente fue denominado "Patrimonio Mundial" (Art.11 de la Convención de 1972). Los efectos primarios y secundarios de la aplicación de este valor son múltiples. El sujeto social invocado como "Humanidad" no ha sido específicamente identificado por la UNESCO en las Convenciones, si bien se supone que acoge a todos los Estados integrados en la Institución internacional. La atribución de tal valor puede considerarse una apropiación por elevación (retórica) que parece no lesionar ni amenazar a la apropiación (real) por las comunidades y los pueblos correspondientes y por los Estados en donde radiquen. Es sabido que tales apropiaciones reales son ejercidas de modo muy desigual, en determinados casos con escasa eficacia y en otros con celosa y obsesiva vigilancia. Por un lado tal valor implica la asunción de la responsabilidad de protección más allá de la que compete a los pueblos de pertenencia del patrimonio, pues incluye la atribución por parte de la propia UNESCO de una especie de legitimación para una intervención subsidiaria a través de la cooperación internacional; por otro lado, intenta preservar a los elementos designados de apropiaciones indebidas (en particular de las que no respetan los derechos de quienes verdaderamente son sus titulares), ya sea por parte de individuos coleccionistas, de compañías multinacionales que explotan patentes, de instituciones culturales acaparadoras o de estados colonialistas, pero a la vez les inviste de una relevancia que ciertamente puede estimular esas y otras apropiaciones (respecto a las que también están protegidas por los instrumentos internacionales de defensa de la propiedad intelectual). Y, sin duda, ha conseguido además orientar hacia ellos corrientes turísticas en algunos casos masivas. Las consecuencias de la inserción de estos lugares en los circuitos turísticos son a menudo buscadas por las propias comunidades y grupos en proyecto de desarrollo, pero igualmente por parte de los Estados con políticas agresivas de atracción turística y por las industrias del ocio. En suma, el número de apropiaciones del Patrimonio Inmaterial puede ser amplio y, en ocasiones, afectan a la autenticidad de los propios elementos.

El Patrimonio Cultural Inmaterial se ha convertido en una especie de capital simbólico en forma similar al que ya lo era el Patrimonio arquitectónico, artístico, histórico..., permitiendo a numerosos pueblos y Estados disfrutar de reconocimientos similares a los que éste ha proporcionado. Sin embargo, conlleva un compromiso mayor pues los elementos para mantenerse vivos necesitan de la implicación como portadores de las comunidades y los grupos sociales. Guardarlos meramente en archivos no sería 
suficiente. Y reproducirlos simplemente como espectáculo sería desvirtuarlos. Es la caracterización de patrimonio "vivo" lo que ha emergido como un valor en sí mismo. Inapreciable valor que en realidad se sitúa en el núcleo del concepto de cultura mientras que mitiga los efectos reduccionistas que casi siempre se traslucen en el concepto de "patrimonio". Y, en todo caso, pone en evidencia esa tensión incómoda que subyace a la cultura entendida como patrimonio, al Patrimonio Cultural. Una etiqueta, un valor de éxito en la modernidad, pero insuficiente -o tal vez injusto- en su concepción pues ha exigido el que se haya llegado a tener que reconocer explícitamente que incluía lo "inmaterial".

\section{Notas}

1. Se recoge en la Conferencia General de la UNESCO en París 1974.

2. En inglés "intangible", que sin embargo deja de traducirse al español como "intangible" y pasa a serlo como "inmaterial", tal y como se registra en el título de la Convención aprobada en 2003.

\section{Bibliografía}

\section{Appadurai, Arjun}

2002 "Diversidad cultural: una plataforma conceptual", Declaración Universal sobre la Diversidad Cultural. UNESCO, Paris. Serie sobre la Diversidad Cultural, $\mathrm{n}^{\circ} 1$.

Francioni, Francesco

2002 "The Protection of Intangible Cultural Heritage: a new Challenge for UNESCO and International Law", Symposium The Transmission and Present State of Cultural Heritage, Kyoto.

2004 "Beyond State Sovereignty: the Protection of Cultural Heritage as a Shared Interest of Humanity", 25 Michigan J. Int. L.: 1209-1229.

Kirshemblatt-Gimblett, Barbara 2004 "Folklore's crisis". The Journal of American Folklore, n 441: 281-327.

1998 "Intangible Heritage as Metacultural Production". Museum, n 221-222: 52-65.

Museum International (Revista)

2004 Intangible Heritage, $\mathrm{n}^{\mathrm{O}}$ 221-222. UNESCO. (Número monográfico dedicado a Patrimonio Inmaterial).

\section{UNESCO}

1972 Convención sobre la protección del Patrimonio mundial, cultural y natural.

1973 Conferencia Intergubernamental sobre las Políticas Culturales en Asia. Yokyakarta

1975 Conferencia Intergubernamental sobre las Políticas culturales en África. Accra.

1978 Conferencia Intergubernamental sobre las Políticas culturales en América. Bogotá.

1982 Declaración de México. Conferencia mundial sobre las Políticas Culturales.

1989 Recomendación sobre la salvaguardia de la Cultural Tradicional y Popular.

1999 Conferencia Internacional "Evaluación global sobre la Recomendación sobre la salvaguardia de la Cultura Tradicional y popular". Washington.

2002 Declaración de Estambul. El Patrimonio Cultural Inmaterial, espejo de la Diversidad cultural.

2003 Convención para la salvaguardia del Patrimonio Cultural Inmaterial. 
(La otra documentación UNESCO citada -listas, proclamación, etc.- se encuentra igualmente en http://www.unesco.org)

Velasco, Honorio M.

2009 "El Patrimonio Cultural como sistema de representación y como sistema de valor", en Carlos Fernández Liesa y Jesús Prieto de Pedro (dir.), La protección jurídico internacional del Patrimonio Cultural. Especial referencia a España. Madrid, Colex: 35-70.

2012 "Las amenazas y riesgos del patrimonio mundial y del patrimonio cultural inmaterial", Anales del Museo Nacional de Antropología, vol. XIV: 10-19. 